\title{
Article \\ Optimal Path Configuration with Coded Laser Pilots for Charging Electric Vehicles Using High Intensity Laser Power Beams
}

\author{
Gunzung Kim ${ }^{+}\left(\mathbb{D}\right.$, Imran Ashraf ${ }^{+}(\mathbb{D}$, Jeongsook Eom and Yongwan Park * \\ Department of Information and Communication Engineering, Yeungnam University, Gyeongbuk, \\ Gyeongsan-si 38541, Korea; gzkim@yu.ac.kr (G.K.); imranashraf@ynu.ac.kr (I.A.); jseom@yu.ac.kr (J.E.) \\ * Correspondence: ywpark@yu.ac.kr \\ + Primary first authors.
}

check for updates

Citation: Kim, G.; Ashraf, I.; Eom, J.; Park, Y. Optimal Path Configuration with Coded Laser Pilots for Charging Electric Vehicles Using High Intensity Laser Power Beams. Appl. Sci. 2021, 11, 3826. https://doi.org/10.3390/ app11093826

Academic Editor: Manuela Sechilariu

Received: 1 April 2021

Accepted: 20 April 2021

Published: 23 April 2021

Publisher's Note: MDPI stays neutral with regard to jurisdictional claims in published maps and institutional affiliations.

Copyright: (c) 2020 by the authors. Licensee MDPI, Basel, Switzerland. This article is an open access article distributed under the terms and conditions of the Creative Commons Attribution (CC BY) license (https:/ / creativecommons.org/licenses/by/ $4.0 /)$.
Abstract: Wireless power transmission (WPT) for wireless charging has been gaining wide attention as a promising approach to miniaturizing the battery size and increasing the maximal total range of an electric vehicle (EV). With an appropriate charging infrastructure, WPT holds great potential to accelerate the acceptance of EVs through users' higher satisfaction, reducing EV cost, and increasing the driving range and capability. A WPT system based on high-intensity laser power beaming (HILPB) provides an optimal solution for wirelessly charging electric vehicles from a distance of several meters. Despite a large number of WPT approaches, the problem of optimal path configuration for charging EV remains an unexplored area. This paper proposes a method to determine the optimal power transmission path in environments where multiple power transmitters (PTXs) and power receivers (PRXs) are operated simultaneously. To this end, we modeled the HILPB power that reaches a PRX equipped with a photovoltaic (PV) array and validated the model by simulating the WPT process in an environment with multiple PTXs and PRXs using a direct-sequence optical code division multiple access (DS-OCDMA) system. In the simulation environment, upon receiving a request from a PRX, a PTX sent its power channel information through optically encoded laser pulses using each available wireless power channel (WPC). The PRX calculated the maximum deliverable power of a PTX and WPC based on the received channel power indicator of the incident laser beam. Based on the calculation results, it selected the optimal PTX and WPC for its maximum power requirement (MPQ). The MPQ of each PRX was satisfied by applying the algorithm for selecting the PTX according to the alignment and characteristics of the PTXs and PRXs. We modeled a power reception model of the PRX based on a PV array using coded laser pilots and validated it through experimentation. We discussed some algorithms that select the most suitable PTX among several PTXs for which several EVs receive the power it needs.

Keywords: DS-OCDMA; optimal path; high-intensity laser power beam; photovoltaic array; wireless power transmission; electric vehicle

\section{Introduction}

Electric vehicles $(\mathrm{EV})$ have been regarded as the future of the automobile and are expected to take over the market of conventional vehicles $(\mathrm{CV})$. CV operates on an internal combustion engine (ICE), which leads to several hazardous environmental issues, including greenhouse gas, global warming, air pollution, etc. [1]. EVs provide the solution to these problems by leveraging the batteries, ultracapacitors, and fuel cells which helps to reduce the environmental issues caused by ICE. Despite their market penetration during the last few years, EV growth depends on several factors. For wide growth and acceptance of $\mathrm{EV}$, the low total cost of ownership (TCO) and charging time has the most significant influence on consumers' purchasing decisions [2]. In the case of an EV, the larger the installed battery's capacity is, the longer it can be used by charging it once [3]. However, as 
the battery's capacity increases, the battery's price increases, and the EV price increases in proportion. On the other hand, there is a disadvantage that fuel economy decreases due to the weight of the battery. The plug-in charging method currently used by EVs is complex, bulky, and accompanies safety issues for users. Besides, it requires a long charging time, causing potential health, safety, and reliability problems. In particular, public charging facilities on the street may be damaged by vandalism and may damage the city landscape.

Wireless power transmission (WPT) for wireless charging is gaining wide attraction from both academia and industry as a promising approach to miniaturize batteries and increase the maximum total range of an EV [4-8]. Qualcomm and other leading companies believe that the convenient and improved user experience brought by the simple, fast charging provided by wireless charging will be the key to the spread of EVs [9-12]. While wireless charging is also essential, a simplified function operated with minimal operator intervention is essential, but high power transfer efficiency (PTE) must be ensured here. The spread of EV wireless charging technology means a significant change in vehicle charging behavior. Drivers charge the EVs little due to time and battery size limitation and dynamic charging can serve as a supplement to charge when stopping, which can relieve anxiety about the range of EVs. In addition, further miniaturizing the battery can play a significant role in reducing the EV's weight and cost [13].

A large body of literature exists on the WPT schemes for wireless charging of EV through different methods, such as inductive coupling and magnetic resonant coupling [14,15]. Predominantly, inductive coupling and magnetic resonant coupling are used for WPT technologies. However, such approaches have a restricted range for optimal electric charging of EV. WPT technology using lasers is a technology that uses high-intensity laser power beams (HILPB) and transmits power generated by solar power generation in space to the ground, transmitting power from the earth to the moon, or is for military use. However, charging through HILPB involves complex processes where the power transmitter (PTX) performs a series of tasks to position the target and power receiver (PRX) accurately [16]. The higher the positioning accuracy of the receiver is, the higher the PTE of HILPB will be, and vice versa. Additionally, the large distance between the PTX and PRX makes the positioning process challenging which affects the PTE of HILPB. To overcome these issues, this study proposes a scheme for selecting appropriate transmitters for HILPB charging and makes the following contributions:

- A power reception model of the PRX using coded laser pilot is proposed and validated through extensive simulations.

- A novel model is proposed for selecting appropriate transmitters from several PTXs, where the PRX uses various wireless power channels (WPC) and coded laser pilots. The proposed algorithm enables developing a simple system because it does not require the PTX to perform a series of processes for positioning the PRX.

- The performance of three different schemes for WPC is analyzed with the proposed algorithm, including PTX selection using the highest PTE first, the least PTE first, and PTX selection based on the best PTE first.

- The photovoltaic (PV) model is validated through simulations and experiments while the path configuration model through simulations using a multi-channel WTP system comprising several PRXs and several PTXs that employ a coded laser pilot and received channel power indicator (RCPI)-based selection system.

The rest of this paper is composed as follows. Background on WPC, description of various technologies used for WPC, and related work are discussed in Section 2. Section 3 proposes a power reception model of the PRX using laser pilot and validates through extensive simulations. Section 4 describes the structure and operation of a multi-laser PTX-PRX system using the proposed method. Section 5 describes two scenarios for HILPB WPT, and the operation of the multiple PTXs and PRXs system is verified by simulation. In the end, the conclusion and future works are given in Section 6. 


\section{Background and Related Work}

The power transmission performance of inductive coupling and magnetic resonant coupling, which are the two most widely studied WPT technologies, is optimal within a range of $1 \mathrm{~m} \mathrm{[7];} \mathrm{thus,} \mathrm{these} \mathrm{technologies} \mathrm{cannot} \mathrm{be} \mathrm{applied} \mathrm{to} \mathrm{EVs} \mathrm{without} \mathrm{modifying}$ the existing road infrastructure. The magnetic induction method has been introduced to charging smartphones which resulted in a reduced price of the products and increased spread of charging devices. Similarly, in the case of an EV, a magnetic resonance method in which energy is transmitted using a magnetic field generated from a coil is commercialized and used to transmit power at a distance of up to several meters. The magnetic induction method is the most efficient WPT method and a PTE of $95 \%$ or more is possible over a distance of several millimeters. The magnetic induction method is mainly used for noncontact types, such as transportation cars, because the power transmission distance is short. The magnetic resonance method is capable of WPT over a distance of several meters, and power transmission efficiency of about $70 \%$ is possible. However, due to the influence of the transmission/reception coil's size and location, it is not easy to commercialize it for EVs.

EV wireless charging methods using WPT currently apply magnetic resonance technology operating in a short distance. This method has high PTE; however, it is essential to embed a PTX on the road for constant charging because it operates in a short distance. For high-speed wireless charging of $\mathrm{EV}$, it is necessary to transmit multiple wireless powers simultaneously. In the magnetic induction and the magnetic resonance methods, for WPT coils are widely used to transmit power to several PRXs using one power transmitter. Despite that, using several PTXs to transmit power to one PRX is very challenging. When using a coil, a pair of coils matching the coil of the PTX must exist, and when there are multiple coils in a narrow space, mutual interference occurs between the coils, making it difficult to find an appropriate match. In EVs, increasing the transmission power is pursued by making multiple transmission/reception pairs using multiple coils.

The long-distance WPT technology that can transmit power over several tens of kilowatts over a distance of several kilometers is still in the early research stage, and a method using microwaves and lasers is used. Microwave and laser-based WPT technologies with far fields greater than or equal to several kilometers used in drones and satellites may be more easily applicable to EVs because the existing road infrastructure can be used without any modifications [9-12]. The microwave method is a technology that transmits high-power energy over a long-distance using a high frequency of several gigahertz. This method requires a very large transmit/receive antenna and has the disadvantage of being harmful to the human body and radio wave interference.

HILPB is applied to fields requiring medium and long-distance power transmission, such as unmanned aerial vehicles. The basic process is the same as that of solar power generation, where the solar panel converts sunlight into electricity. The key difference is that the WPT system uses a highly concentrated laser beam, rather than sunlight and aims at a specialized solar panel that converts the laser beam into electricity. Additionally, the laser beam can have higher energy than the sunlight and it can be directed at any point in the line-of-sight of the transmitter. While WPT technologies using microwaves have several constraints owing to radio frequency interference, those using laser beams have advantages of zero interference and simultaneous power delivery from multiple power sources [17]. However, WPT technologies for EVs require high electrical power, which poses significant safety concerns $[18,19]$, such as the risk of exposure to high electromagnetic energy. The inherent ability of lasers to produce a focused and directed energy beam makes the laserbased WPT system hazardous [20,21]. The American National Standard Institute (ANSI) for Safe Use of Lasers (ANSI Z136.1) provides guidelines for preventing beam and electrical hazards while working with laser systems [22].

HILPB can transmit power from several tens of kilometers away as long as EVs have devices, such as solar panels that can receive laser power beams, so there is no need to change infrastructure, such as existing roads. When stopping at a crossroad or crosswalk to wait for a signal, if the HILPB WPT device mounted on a traffic light provides instantaneous 
high power, it is possible to continuously charge even with a small battery. In this method, the received power is determined according to the PTX's distance, incidence angle, the solar panel area, and the power conversion efficiency of PRX. HILPB is a characteristic of a laser and solar panel so that multiple PTXs can transmit power to a single PRX, such as a PV array. Since lasers do not interfere with each other, there is not interference even if multiple PTXs are concentrated. Fast wireless charging of an EV requires simultaneous transmission of concentrated power from multiple PTXs. In coil-based magnetic induction and magnetic resonance technologies, multiple PRXs are often used for power transfer from one PTX. However, using multiple PTXs for power transfer to one PRX is a significant technical challenge [23-27]. In a multi-coil-based WPT system, the PTX and PRX coils should be aligned and many coils packed in the near field are prone to mutual interference, making it difficult to find an appropriate power transmission point. Therefore, enhancing the transmission power using multiple PTX/PRX coil pairs is a hot topic in EV research. A laser-based WPT system, on the other hand, enables simultaneous transmission of concentrated power from multiple PTXs to one PRX concerning the nature of lasers and the use of a PV array. Without any interference between laser beams, no mutual interference can occur even between multiple laser beams that are directed toward one single spot. If a $\mathrm{PV}$ array simultaneously receives multiple laser power beams, the sum of the delivered power of all beams is proportional to the total received power transmission without any power loss unless it exceeds the maximum power generation capacity of the PV array used. With the development of related technologies, the possibility of practical use of the HILPB system is increasing. However, the efficiency of the overall power transmission system is only about $10 \%$ to $20 \%$, which is the biggest obstacle to the practical use of HILPB. In the case of capacitive power transfer, which is a short-range wireless charging method, the efficiency of the overall power transmission system reaches up to $90 \%$. As the technology evolves, the possibility of the HILPB applications is becoming an increasing reality [28].

Conventionally, a WPT system based on HILPB requires the PTX to perform a series of processes to accurately position the target and the PRX equipped with a specialized reflector or concentrator $[16,29,30]$. The PTE of HILPB can be maximized only after the receiver is positioned accurately. The positioning process is erroneous and a large distance between the PTX and PRX makes the accurate positioning of the PRX even more challenging. Significant research efforts are in progress for accurate positioning of the PRX due to its importance for higher PTE. To resolve these issues, we propose selecting appropriate transmitters from several PTXs, where the PRX uses various WPC and coded laser pilots. When there are multiple PRXs and multiple PTXs in a HILPB WPT system, a laser pilot coded with direct-sequence optical code division multiple access (DS-OCDMA) is used to receive the power required by the PRX. The PRX calculates the RCPI of every received laser pilot to select the WPC with the highest power and then sends the information about the selected WPC to the PTX. Using a HILPB WPT system and comprising multiple PTXs and PRXs as in an EV, the proposed method selects the optimal PTX from a group of PTXs best suited for any given PRX in a group of PRXs to satisfy the maximum power requirements (MPQs). We modeled the PTX-to-PRX power transmission and validated the model by simulating the operation of a multi-channel WTP system comprising several PRXs and several PTXs that employ a coded laser pilot.

\section{Received Power Model of a PV Array with Experimental Validation}

\subsection{Modeling of Received Power at PV Array}

Zhou and Jin proposed a PV array model under the Gaussian laser beam condition [31]. In their propose model, the PV array is a network of dimensions $m \times n$, where $m$ and $n$ represents the number of PV cells in the column and row, respectively. Figure 1a illustrates the arrangement of individual PV cells, and Figure 2a shows the calculated normalized irradiance profile model on each numbered PV cell in a $5 \times 5$ PV array. Based on Zhou's PV array model and the properties of 5S1010.4-A555555 of MHGP's standard VMJ PV array product [32], we modified and added some definitions to cover the off-centered position 
and the electrical output power of the PV array, as illustrated in Figures 1b-d [33-35]. Figures $2 \mathrm{a}-\mathrm{d}$ also show the distribution of normalized irradiance with an off-centered position and different laser beam spot radii in a $5 \times 5 \mathrm{PV}$ array according to Table 1 .

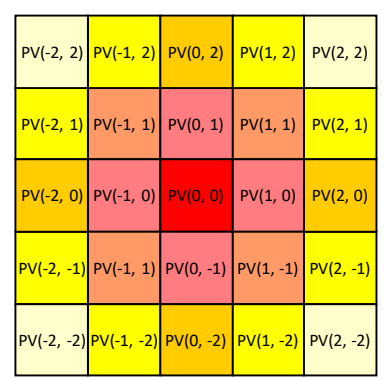

(a)

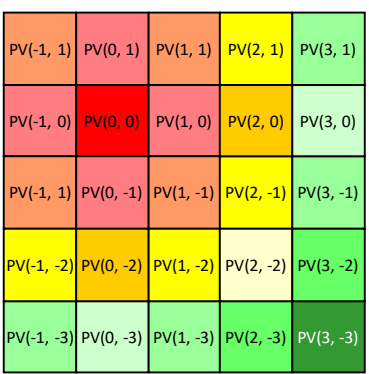

(b)

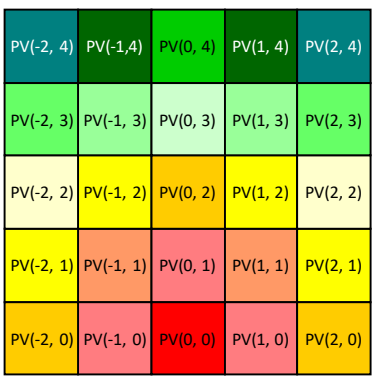

(c)

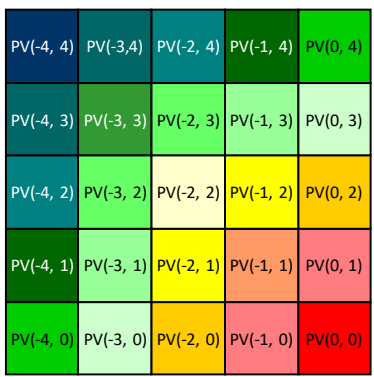

(d)

Figure 1. Cell arrangement in a $5 \times 5 \mathrm{PV}$ array: highest irradiance cell is located at (a) center position $(3,3)$, (b) upper left side $(2,2)$, (c) bottom center side $(5,3)$, and (d) bottom right side $(5,5)$.

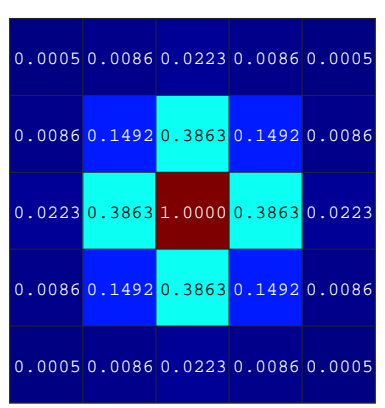

(a)

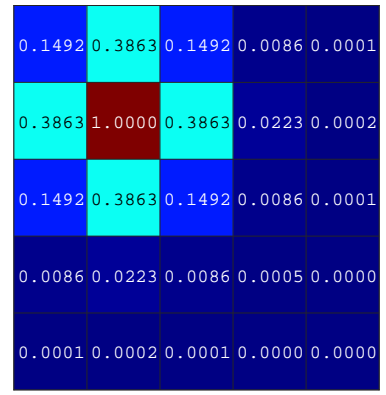

(b)

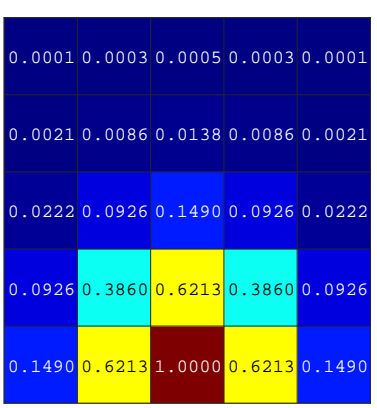

(c)

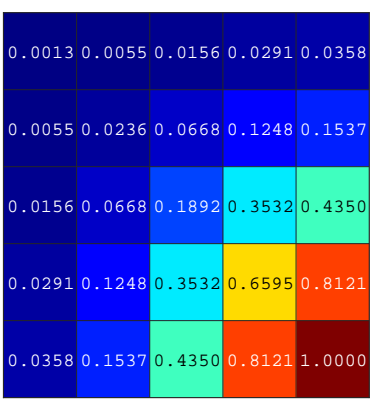

(d)

Figure 2. Distribution of normalized irradiance profile model for a $5 \times 5$ PV array: highest irradiance cell is located at (a) center, (b) upper left side, (c) bottom center side, and (d) bottom right side.

Table 1. Four experimental setups to validate a mathematical model.

\begin{tabular}{ccccc}
\hline Parameter & Setup \#1 & Setup \#2 & Setup \#3 & Setup \#4 \\
\hline $\begin{array}{c}\text { Distance between } \\
\text { laser and PV array }\end{array}$ & $7 \mathrm{~m}$ & $7 \mathrm{~m}$ & $7 \mathrm{~m}$ & $7 \mathrm{~m}$ \\
\hline $\begin{array}{c}\text { Spot radius on } \\
\text { PV array surface }\end{array}$ & $\begin{array}{c}1.45 \mathrm{cell} \\
(29 \mathrm{~mm})\end{array}$ & $\begin{array}{c}1.45 \mathrm{cell} \\
(29 \mathrm{~mm})\end{array}$ & $\begin{array}{c}1.45 \text { cell } \\
(41 \mathrm{~mm})\end{array}$ & $\begin{array}{c}1.45 \mathrm{cell} \\
(62 \mathrm{~mm})\end{array}$ \\
\hline Laser power & $6 \mathrm{~W}$ & $6 \mathrm{~W}$ & $6 \mathrm{~W}$ & $6 \mathrm{~W}$ \\
\hline $\begin{array}{c}\text { Location of highest } \\
\text { irradiation cell }\end{array}$ & $\begin{array}{c}\text { Center } \\
(\text { Figure 1a) }\end{array}$ & $\begin{array}{c}\text { Upper } \\
\text { left side } \\
\text { (Figure 1b) }\end{array}$ & $\begin{array}{c}\text { Bottom } \\
\text { center side } \\
\text { (Figure 1c) }\end{array}$ & $\begin{array}{c}\text { Bottom } \\
\text { right side } \\
\text { (Figure 1d) }\end{array}$ \\
\hline
\end{tabular}

$P V(0,0)$ is the position of the cell with the highest irradiance in the PV array, and each $P V(i, j)$ represents an individual PV cell, where index $i$ and $j$ represent the distances from $P V(0,0)$ in the PV array. The distance $D_{i, j}$ between $P V(i, j)$ and $P V(0,0)$ can be defined by Equation (1).

$$
D_{i, j}=\sqrt{i^{2}+j^{2}}
$$


In each PV cell, the normalized irradiance $\left(\frac{G_{i, j}}{G_{0,0}}\right)$ ranges from 0 to 1 and can be specified using Equation (2).

$$
\frac{G_{i, j}}{G_{0,0}}=e^{-\frac{2 D_{i, j}^{2}}{\omega_{0}^{2}}}
$$

$\omega_{0}$ is the spot radius of the laser beam from PTX on the target surface, as defined by Equation (3).

$$
\omega_{0}=\frac{D_{L}+\alpha_{T} R_{T}}{\cos \theta_{T}},
$$

where the entities in Equation (3) are as follows:

- $D_{L}$ : diameter of the transmitted laser beam $(\mathrm{m})$;

- $\quad \alpha_{T}$ : divergence angle of the transmitted laser beam ( $\left.\mathrm{rad}\right)$;

- $R_{T}$ : distance between PTX and PRX (m);

- $\theta_{T}$ : incident angle of the laser beam on the PV array $\left(^{\circ}\right)$.

$G$ is the sum of the irradiance of each cell in the PV array with transmitted power PTX, as defined by Equation (4).

$$
G=\sum_{i=m_{0}}^{i=m} \sum_{j=n_{0}}^{j=n} G_{i, j}=G_{0,0} \sum_{i=m_{0}}^{i=m} \sum_{j=n_{0}}^{j=n} \frac{G_{i, j}}{G_{0,0}}=\frac{2 P_{T X}}{\pi \omega_{0}^{2}} \sum_{i=m_{0}}^{i=m} \sum_{j=n_{0}}^{j=n} e^{-\frac{2 D_{i, j}^{2}}{\omega_{0}^{2}}} .
$$

The received power will be converted from the irradiated energy $(G)$ on a given target surface $(A)$ of the PV array with a photovoltaic power conversion (PPC) rate $\left(\tau_{P P C}\right)$ and can be obtained from Equation (5).

$$
P_{R X}=G \times A \times \tau_{P P C}=A \tau_{P P C} \frac{2 P_{T X}}{\pi \omega_{0}^{2}} \sum_{i=m_{0}}^{i=m} \sum_{j=n_{0}}^{j=n} e^{-\frac{2 D_{i, j}^{2}}{\omega_{0}^{2}}} .
$$

\subsection{Experimental Validation of Received Power Model}

To validate a mathematical model of the received power on an LPBRX with a $5 \times 5$ VMJ PV cell array, we experimented with a 5S1010.4-A555555 from MHGP's standard VMJ PV array product and an MDL-H-808 from Opto Engine LLC. Experimental setup to validate the received power model is shown in Figure 3.

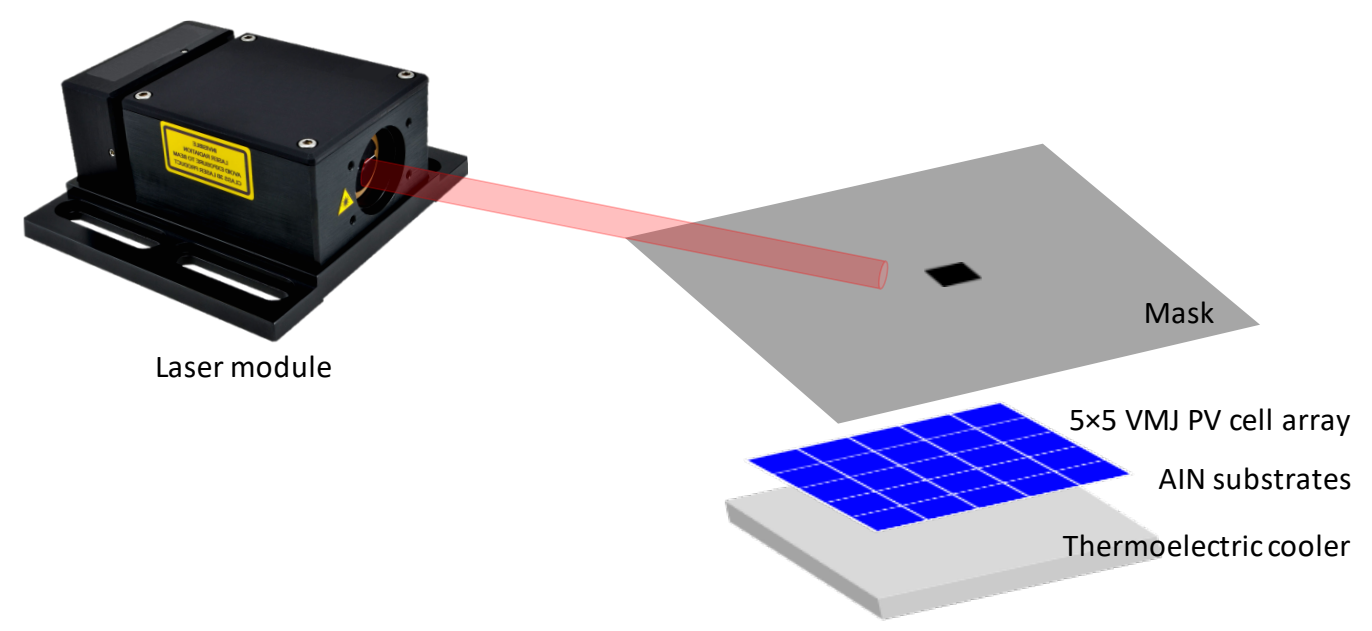

Figure 3. Experimental setup to validate the mathematical model.

The 5S1010.4-A555555 is suitable for HILPB applications requiring power up to $160 \mathrm{~W}$ at $975 \mathrm{~nm}$ with up to $36 \%$ power conversion efficiency. It consists of a $5 \times 5$ array of VMJ 
PV cells with an active cell area of dimensions $51 \mathrm{~mm} \times 52 \mathrm{~mm}$. It is mounted to aluminum nitride (AlN) substrates that have a PPC functionality and converts laser beams to electric powers without further additions. We mounted the VMJ PV array onto a commercial off the shelf (COTS) thermoelectric cooler (TEC) with the liquid cooling plate to keep the array temperature around $25{ }^{\circ} \mathrm{C}$. The MDL-H- 808 is an infrared laser module at $808 \mathrm{~nm}$ with $6 \mathrm{~W}$ output power. Table 1 describes the four experimental setups when the laser module has located away from the VMJ PV cell array, and Table 2 shows the detailed technical specifications of the 5S1010.4-A555555 VMJ PV cell array and the MDL-H-808 laser module.

Table 2. Technical specifications of the 5S1010.4-A555555 VMJ PV cell array and MDL-H-808 laser module.

\begin{tabular}{cc}
\hline & 5S1010.4-A555555 \\
\hline Parameter & Value \\
Technology & Photovoltaic receiver \\
Optimal wavelength & $975 \mathrm{~nm}$ \\
Input power & Up to $50 \mathrm{~W} \mathrm{~cm}^{-1}$ \\
Output power & Up to $160 \mathrm{~W}$ \\
Power conversion efficiency $\left(\tau_{P P C}\right)$ & Up to $36 \%$ \\
Dimension $(\mathrm{A})$ & $51 \mathrm{~mm} \times 52 \mathrm{~mm}$ \\
Unit price & $\$ 2000$ \\
\hline Parameter & MDL-H-808 \\
Technology & \\
Wavelength & Value \\
Operation mode & DPSS laser \\
Output power $\left(P_{T \text { Tax }}\right)$ & $808 \mathrm{~nm}$ \\
Beam diameter $\left(D_{L}\right)$ & Continous wave \\
Beam divergence $\left(\alpha_{T}\right)$ & $3 \mathrm{~W}$ to $6 \mathrm{~W}$ \\
Unit price & $8 \mathrm{~mm}$ \\
& $3 \mathrm{mrad}$ \\
& $\$ 1200$ \\
\hline
\end{tabular}

Figure 4 illustrates the received power distribution of the four experimental setups The sums of received power are $1.8298 \mathrm{~W}, 1.8370 \mathrm{~W}, 1.9745 \mathrm{~W}$, and $2.0780 \mathrm{~W}$ that depend on the location of the highest irradiance cell, respectiveley. Figure 5 shows the normalized power distribution relative to the highest irradiance cell.

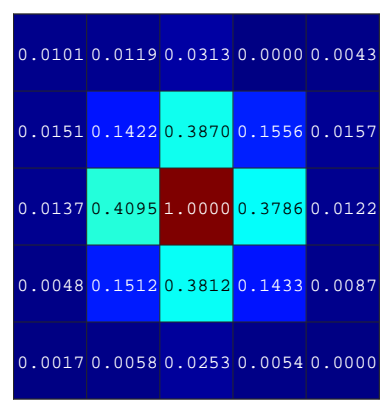

(a)

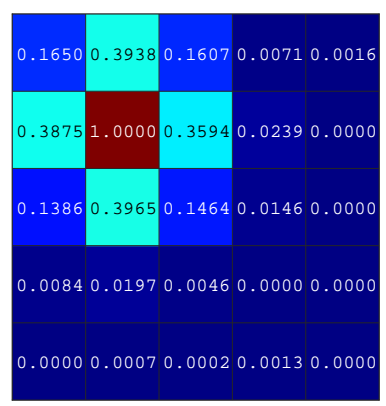

(b)

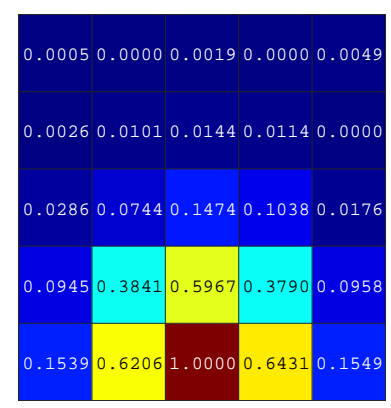

(c)

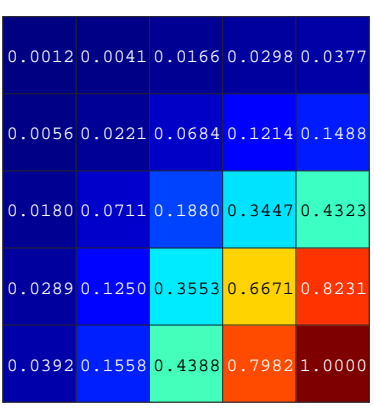

(d)

Figure 4. Received power when the laser module MDL-H-808 was located away from the 5S1010.4-A555555 VMJ PV cell array: suitable experimental setup in Table 1 is (a) setup \#1, (b) setup \#2, (c) setup \#3, and (d) setup \#4. 


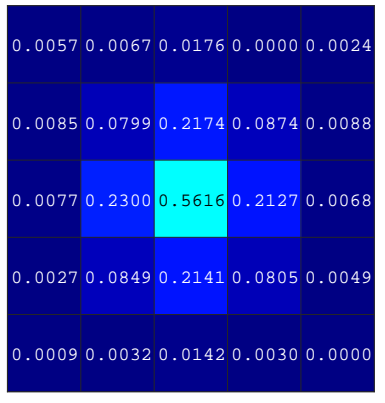

(a)

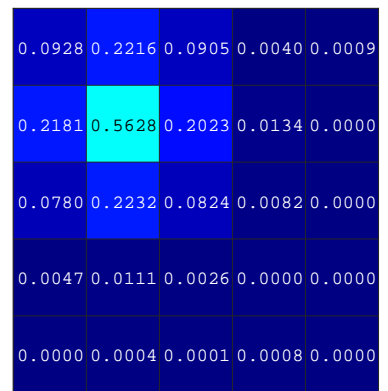

(b)

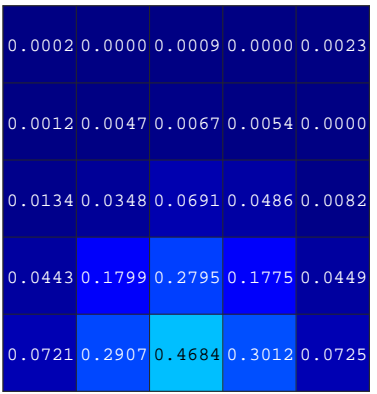

(c)

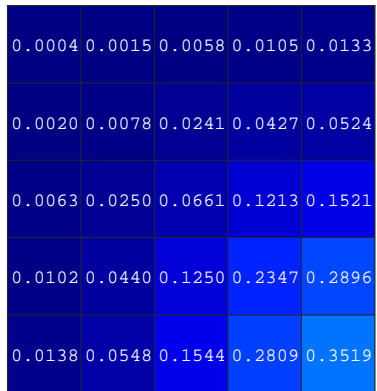

(d)

Figure 5. Normalized energy—irradiance-distribution relative to the highest irradiance cell when the laser module was located away from the VMJ PV cell array: suitable experimental setup in Table 1 is (a) setup \#1, (b) setup \#2, (c) setup \#3, and (d) setup \#4.

Compared with the mathematical model and measured values in Figures 6 and 7 and Table 3, it can be seen that the error between the mathematical model and measured values is negligible. Considering the factors of the performance difference between the VMJ PV cells and the actual Gaussian HILPB, it can be concluded that the irradiance profile model is valid and practical.

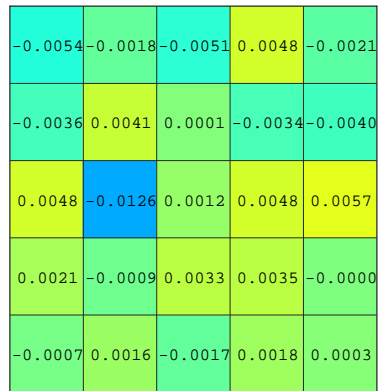

(a)

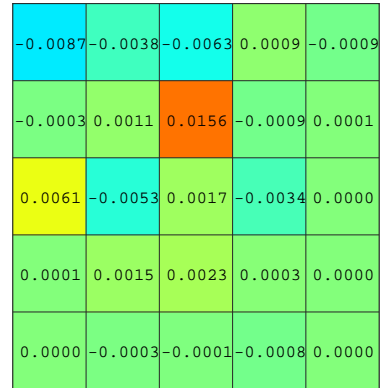

(b)

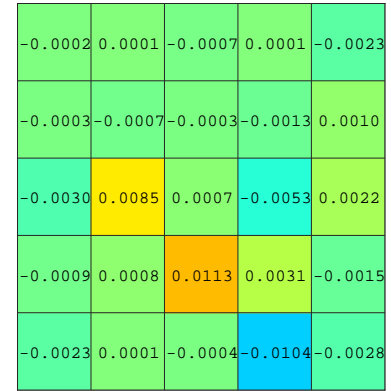

(c)

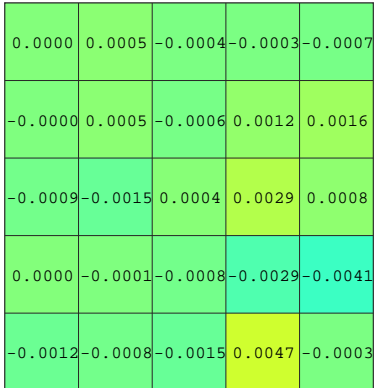

(d)

Figure 6. Compared power distribution between the mathematical model and measured values: suitable experimental setup in Table 2 is (a) setup \#1, (b) setup \#2, (c) setup \#3, and (d) setup \#4.

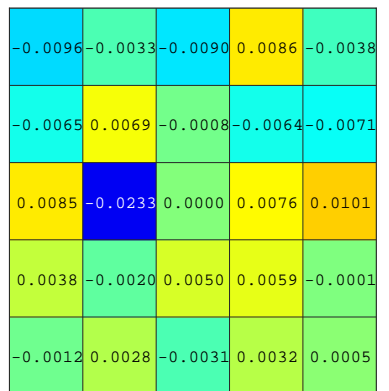

(a)

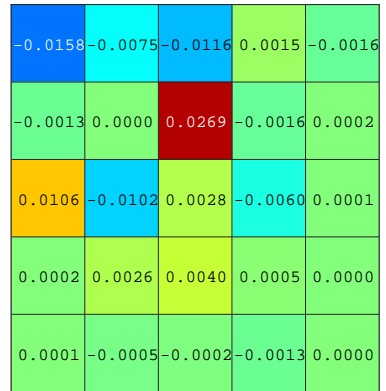

(b)

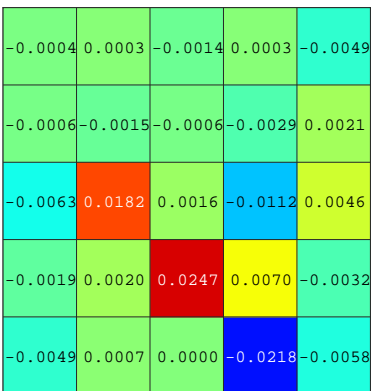

(c)

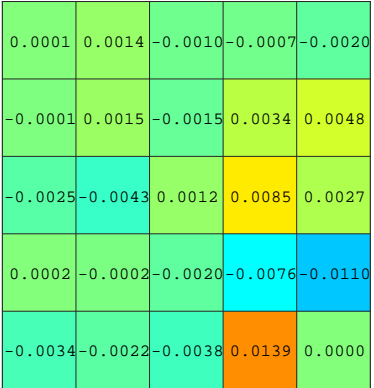

(d)

Figure 7. Compared irradiance distribution between the mathematical model and measured values: suitable experimental setup in Table 2 is (a) setup \#1, (b) setup \#2, (c) setup \#3, and (d) setup \#4. 
Table 3. Standard deviation of the difference between the mathematical model and measured values.

\begin{tabular}{ccccc}
\hline Suitable Experimental Setup & Setup \#1 & Setup \#2 & Setup \#3 & Setup \#4 \\
\hline Standard deviation of irradiation & 0.0098 & 0.0067 & 0.0068 & 0.0052 \\
Standard deviation of power & 0.0053 & 0.0037 & 0.0029 & 0.0019 \\
\hline
\end{tabular}

\section{Structure and Operation of Coded Laser Pilots-Based HILPB WPT System}

The proposed HILPB WPT system comprises of multiple PTXs and PRXs. PTXs mounted on traffic lights at intersections perform vehicle-to-infrastructure (V2I) communication with EVs. Upon receiving a request from an EV, a PTX sends its power channel information (PCI) as a coded laser pilots using each available WPC. The EV selects a PTX based on the PCI. The selected PTX emits HILPB using the designated WPC, which is a laser beam propagation path from a PTX to a PRX and its location is expressed by the spherical coordinates of the laser emission angle.

The energy conversion efficiency is decreased with increased PV cell temperature and a large part of the absorbed laser energy would dissipate into heat. According to the law of energy conservation, the sum of the thermal-related energy from light-to-heat generation and the electrical energy from light-to-electricity conversion should basically equal the absorbed laser power. These two energy forms of thermal and electrical energy are intrinsically competing for counterparts. The temperature and the thermal stress in the PV array are determined by the heat generated from the absorbed laser energy, which in turn instantaneously determine the light-to-electricity conversion efficiency. The higher the convective heat transfer, the more electrical power would be obtained. The PV array is located on the top of the roof. PTX is placed at the traffic light which is a higher place than the vehicle, so the roof is best seen in a line of sight at traffic signals. The roof is the flattest and widest part of the vehicle. The wider the roof, the more PV array can be installed, and the more power can be received, the more energy can be received. Because the roof is exposed to the outside, it has an excellent natural heat dissipation effect through convection, and artificial cooling using various methods is also possible [36].

The PRX mounted on the EV performs V2I communication with the surrounding infrastructure, including traffic lights, and converts the HILPB received from the PTX via an embedded PV array into PCI or power. To avoid hazards due to the HILPB, the EVs are not in motion and are halted at the intersections, waiting for the signal to turn green. When the power supply is drained, the PRX receives and analyzes the PCI sent by the PTXs and selects the optimal PTX and WPC for power transmission. Figure 8 illustrates the overall structure of an HILPB-based multiple WPT environment comprising four PRXs and 12 PTXs. Each of the four PTXs at each crossroad has its maximum transmission power (MTP) and WPC, and the transmission distance and incident angle vary according to the geometric relationship between the PTX and PRX, resulting in different amounts of power delivered to the PRX at each transmission event. Depending on the amount of required power, a PRX can generate more than one power transmission path by selecting more than one PTX. 


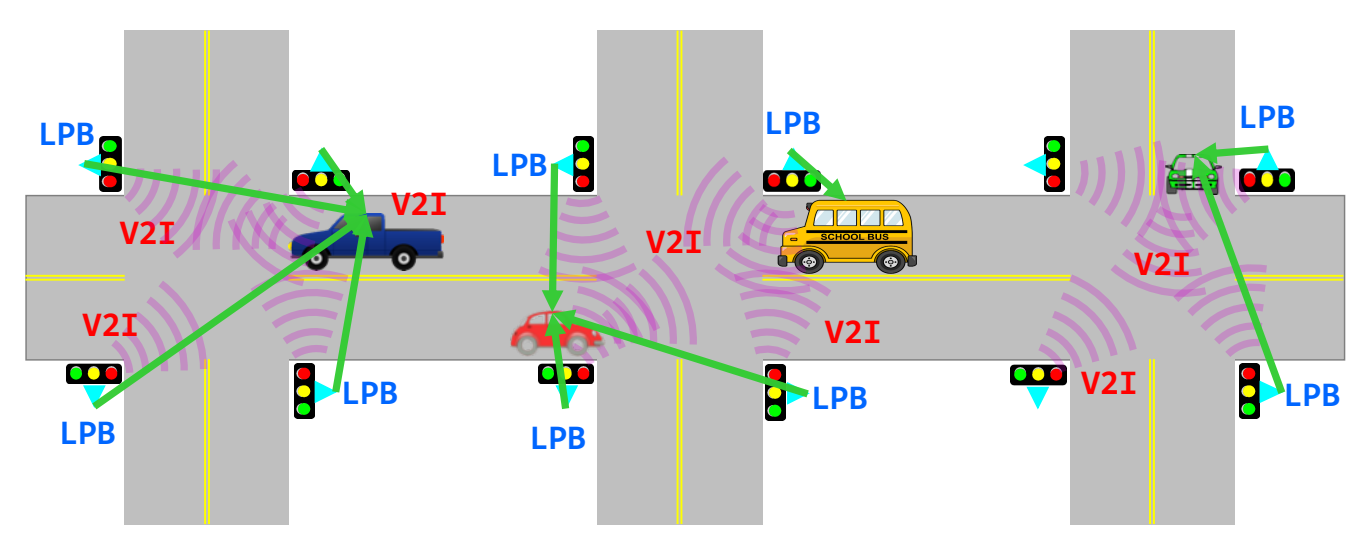

Figure 8. Block diagram of a multiple WPT environment using HILPB and V2I transmission.

However, one of key problems is the accurate positioning of the PTX and PRX to achieve the highest PTE. If the positioning is not accurate, it leads to power losses and consequently a low PTE is obtained. Figure 9 shows a scenario involving four PTXs and one PRX where the positioning is not proper on the PV array. The circled area outside the PV array leads to the power losses and reduces the PTE. In the given scenario, only T1 can provide the highest PTE concerning its positioning accuracy with the PV array, while T1, T2, and T3 lead to power losses, assuming that all PTXs possess the same power capacity.

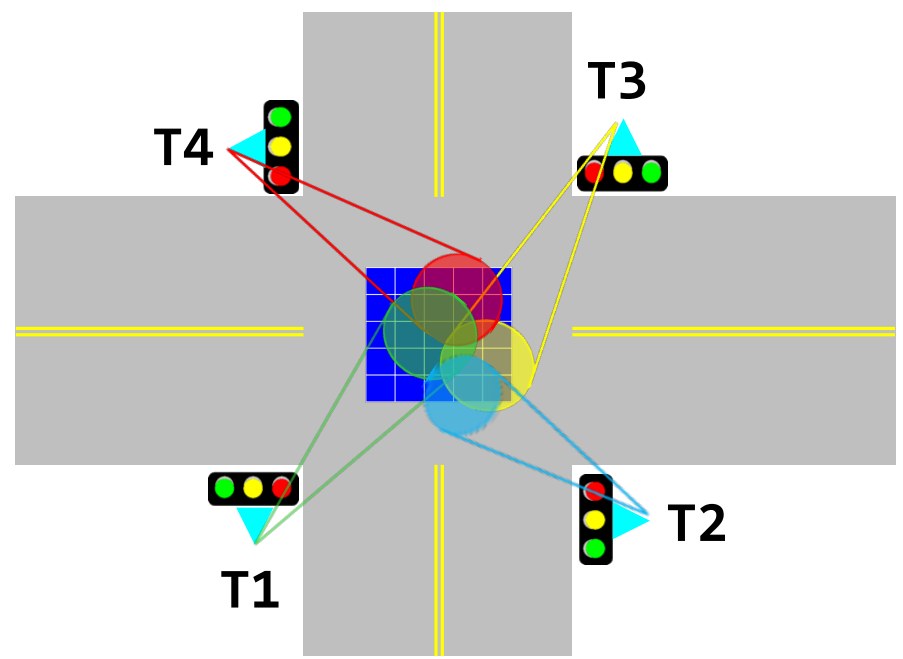

Figure 9. Scenario showing the power losses caused by positioning inaccuracy between the PTXs and PRX.

\subsection{Power Transmitter (PTX)}

A PTX is a device mounted on a traffic light for V2I communication between the HILPB-based WPT and EVs, and uses a spherical coordinates as shown in Figure 10. A 36 bit PCI specific to each PTX comprising 1 bit is allocated to the start signal, 5 bit each are allocated to the PTX ID and PRX ID, 7 bit each to the IDs of the two parts (polar angle $\theta$ and azimuthal angle $\phi$ ) of the WPC available for transmission, 8 bit to the MTP per $10 \mathrm{~W}$, and 3 bit to checksum or cyclic redundancy check (CRC), as shown in Figure 11. The WPC IDs indicate the emission direction of the laser beam in the spherical coordinate system. The CRC, which is used for detecting accidental changes in PCI, can be generated from the PRX ID, PTX ID, WPC, and MTP. 


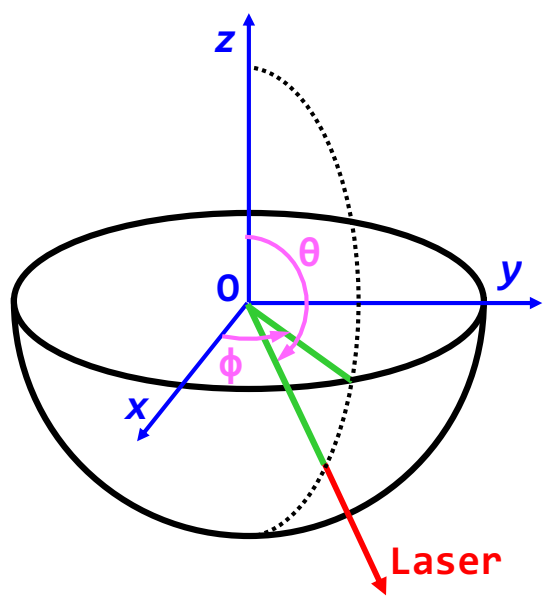

Figure 10. Laser beam direction and position as determined for each PTX channel.

\begin{tabular}{|l|c|c|c|c|c|c|}
\hline 1 & 5 & 5 & 7 & 7 & 8 & 3 \\
\hline \hline${ }_{1}$, & RX ID & TX ID & Polar angle $(\theta)$ & Azimuth $(\phi)$ & Max Power & CRC \\
\hline \hline MSB
\end{tabular}

Figure 11. Unique PCI packet format transmitted from a PTX.

The PTXs transmit their respective PCI to the PRXs through laser beams within the Class 1 maximum permissible exposure (MPE) range in the detection step and transmit their MTP through HILPB in the transfer step. They receive messages from the PRXs in real-time around the clock via V2I communication. DS-OCDMA has been designed to provide multiple and simultaneous access to optical systems. DS-OCDMA has been examined already in environments requiring an address or user identification in various optical applications [37-43]. The PCI transmitted from a PTX comprises DS-OCDMAencoded data designed to make one PCI orthogonal to the others, given that different sets of information are simultaneously sent from multiple PTXs. DS-OCDMA uses spread spectrum communication and digital modulation. The former is based on a unipolar synchronous prime sequence code and the latter is based on the nonreturn-to-zero (NRZ) on-off keying (OOK). Assigning a unique code to each of the 25 PTXs with different 5 bit device ID numbers is ensured by using synchronous prime sequence codes with a weight of 7 and a code length of 49 .

The operation of a PTX is divided into standby, detection, and transfer steps as marked in red, green, and blue, respectively, in Algorithm 1. In the standby step, the PTX is waiting for a PCI request message via V2I from a PRX. On receiving a PCI request message, it proceeds to the detection step and transmits its unique PCI encoded with DS-OCDMA in a laser beam within Class $1 \mathrm{MPE}$, which constitutes a safe level of exposure. A PTX sequentially transmits one encoded PCI after another using one channel each from the WPCs available for transmission. While all PTXs simultaneously proceed with the detection step on receiving a PCI request message, they have different end times because the number of WPCs available varies from one PTX to another. Upon completion of PCI transmission via all available WPCs, the PTXs return to the standby step and only the ones that receive the transfer start message from a PRX initiates the transfer step. A PRX analyzes the PCI transmitted by the PTXs in the detection step, selects the optimal PTX, and sends a transfer start message to the selected PTX, thereby designating the WPC for the given transmission. Thus, the selected PTX transmits the MTP through HILPB using the designated WPC. Upon receiving the transfer stop message from the PRX, it stops the transmission and returns to the standby step. EVs in the near future are constantly monitoring the outside of the vehicle through various sensors, such as radar or LiDAR, so it is possible to predict the occurrence of accidents caused by a collision. In addition, the vehicle can immediately 
detect an external shock, such as a collision of another vehicle or motorcycle, and this can be requested to stop the power supply to the PTX through V2I.

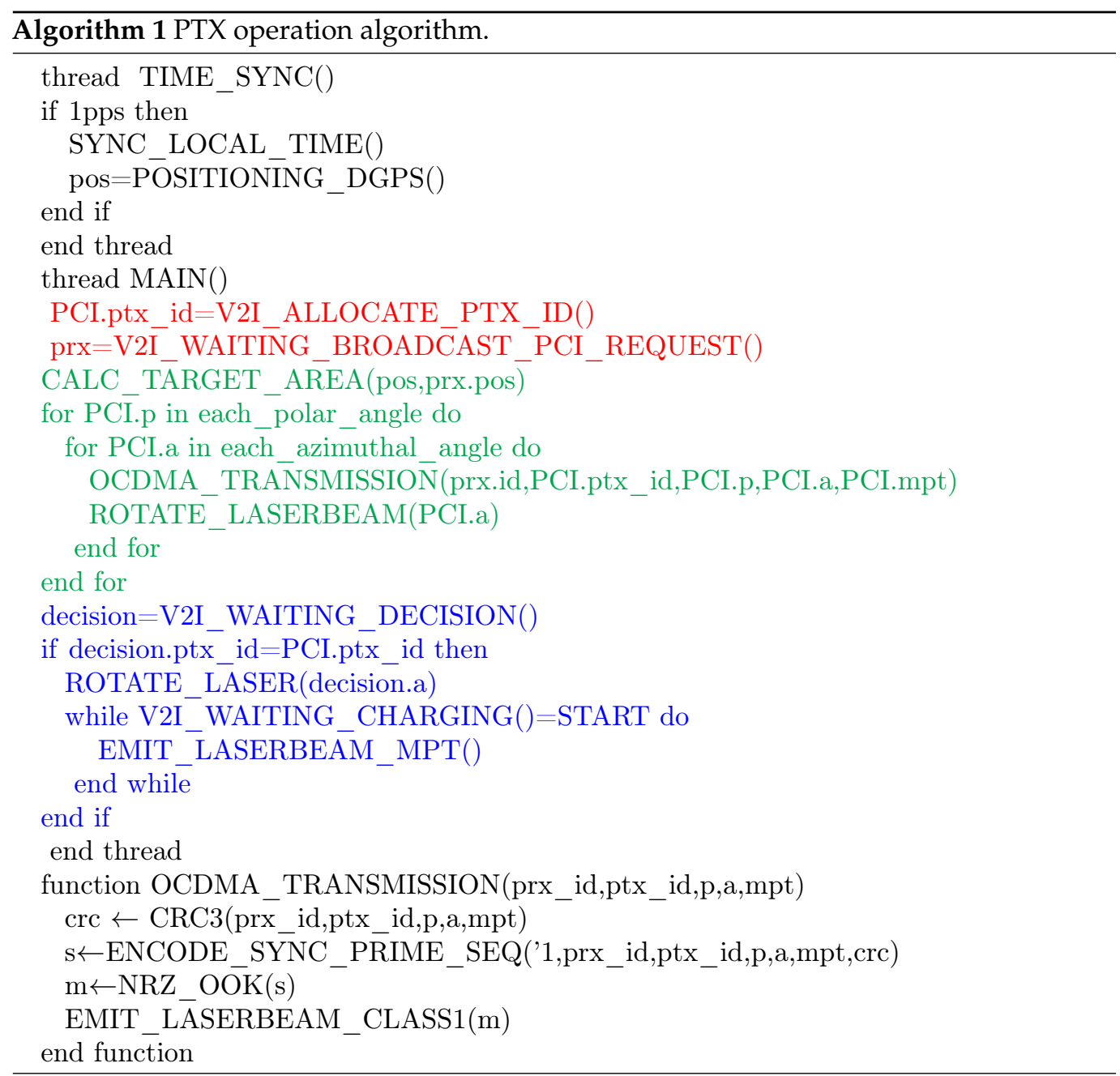

\subsection{Power Receiver (PRX)}

An EV communicating with traffic lights via V2I functions as a PRX. It receives HILPBs transmitted from PTXs using a PV array and converts them into electricity for power supply. It can broadcast PCI request messages, transfer start messages, and transfer stop messages to PTXs via V2I communication. It receives and decodes the unique PCI sent from a PTX through its designated WPC using the DS-OCDMA system and calculates the maximum deliverable power (MDP) of a PTX and WPC on the basis of the RCPI of the incoming laser beam. Based on the calculation results, it selects the optimal PTX and WPC best suited for its MPQ.

The operation of a PRX is divided into standby, detection, and transfer steps as marked in red, green, and blue, respectively, in Algorithm 2. In the standby step, the PRX does not receive any laser beams. It proceeds to the detection step and broadcasts a PCI request message via V2I whenever an MPQ is detected. In the detection step, the PRX receives the $\mathrm{PCI}$ from each of the PTXs responding to its PCI request message, thereby recording the RCPI. Thus, the data received are decoded with DS-OCDMA, followed by checksum (CRC) comparison and storage of errorless PCI along with RCPI. RCPI varies from an incoming laser beam to another depending on the distance between the PTX and PRX, the laser beam incident angle, and the power distribution in the PV array, because each PTX transmits its unique PCI within the range of Class 1 MPE per pulse. The MDP from a PTX through a particular WPC can be calculated using the RCPI. Among the parameters in Equation (6), 
the laser power $\left(P_{\text {Tclass } 1}\right)$ is within Class $1 \mathrm{MPE}$ per pulse; however, it becomes the MDP when HILPB is transmitted. Because the PV array area $(A)$ is a characteristic of the PRX, all PTXs have the same values for the same PRX. Therefore, the calculation of the PTE $\left(\tau_{s y s}\right)$ based on the RCPI, which varies from one PTX to another in the detection step, can be simplified to Equation (6).

$$
\tau_{\text {sys }}=\frac{P_{R}}{P_{\text {Tclass } 1}} .
$$

Using the PTE calculated on the basis of the RCPI during the detection period, the amount $(U)$ of MDP of the PRX at the MTP $\left(P_{T \max }\right)$ can be defined by Equation (7).

$$
U=P_{\text {Tmax }} \times \tau_{\text {sys }} .
$$

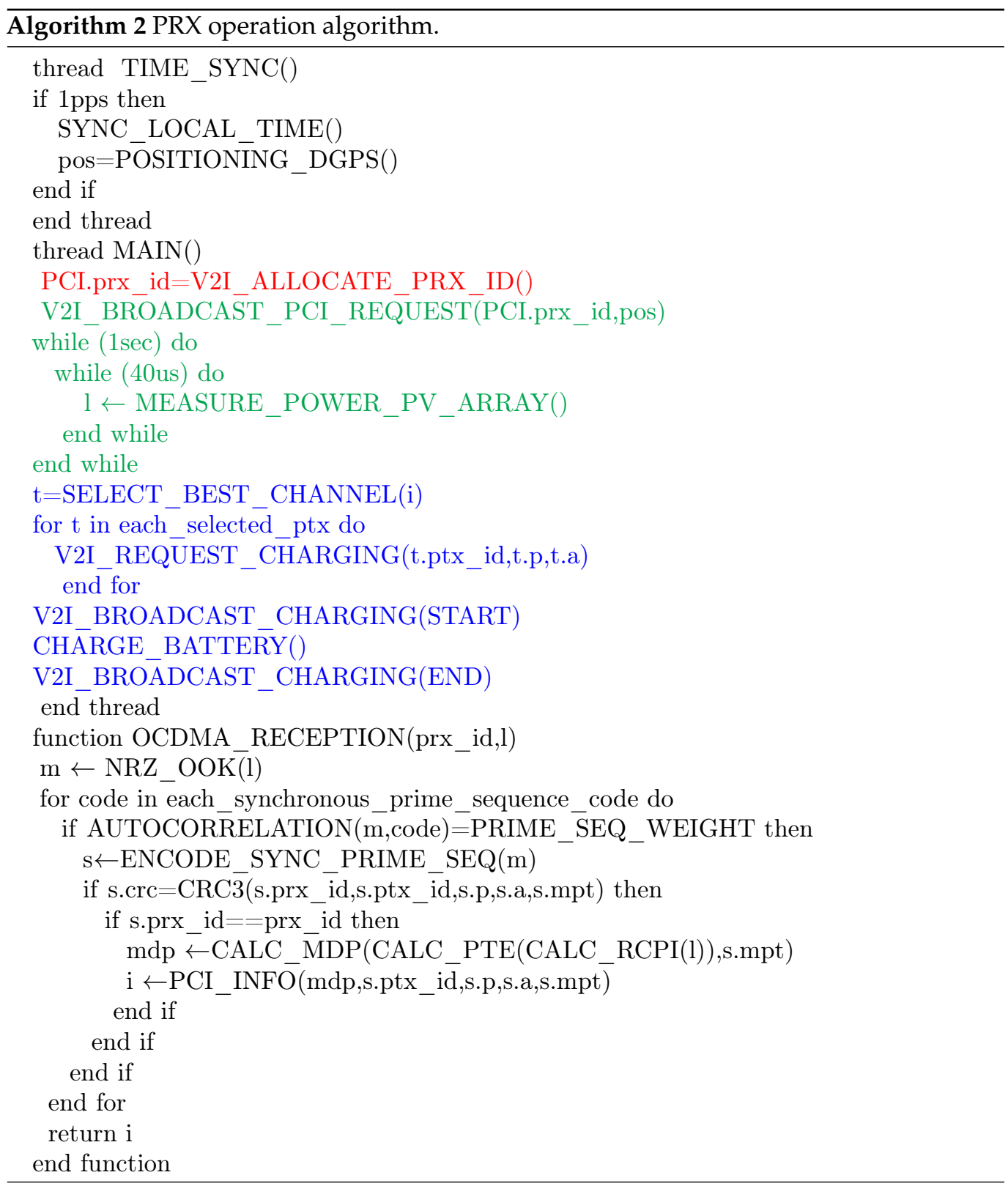

The PRX establishes the optimal power transmission path by selecting the optimal PTX and WPC based on the amount of MDP of each PRX through each designated WPC calculated by substituting each PTX's unique PCI and RCPI into Equations (6) and (7). The PRX then proceeds to the transfer step by sending the transfer start message to the selected 
PTX along with the PCI on the designated WPC. If the MDP of one PTX does not meet it's $M P Q$, the PRX sends the transfer start message to two or more PTXs, distributing the total amount of required power supply among them. The PRX converts the HILPB received through the PV array into electricity for power supply. If the desired MPQ is met, the PRX sends a transfer stop message to the PTX. When all PTXs stop power delivery, the PRX returns to the standby step and stays in the standby mode until an MPQ is sensed. PRXs and PTXs undergo the process to establish the optimal power transmission path, as illustrated in Algorithms 1 and 2 and Figure 12.

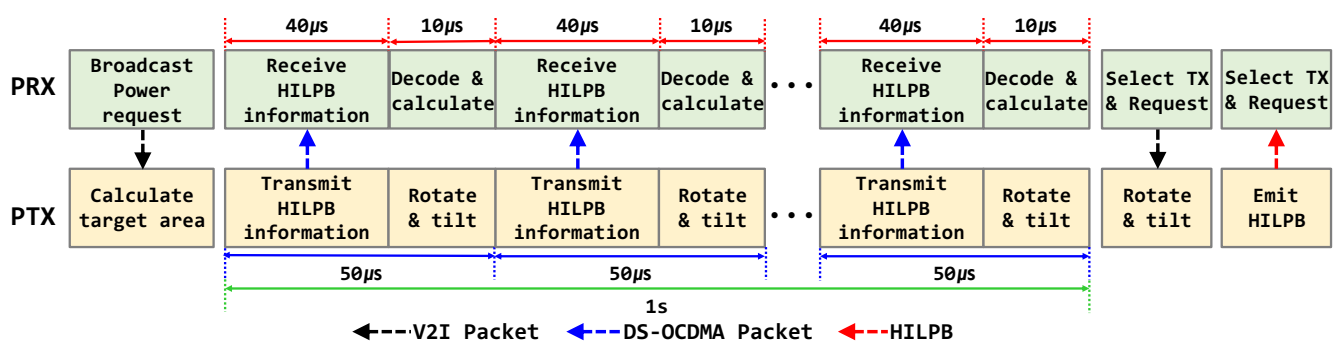

Figure 12. Timeline for WPT protocol.

\section{Simulation of Coded Laser Pilots-Based HILPB WPT System}

\subsection{Simulation Environment}

The simulation was performed by placing three PRXs (R1 to R3) that require different MDP and MPQ and four PTXs (T1 to T4) with different MTP, as shown in Figure 13. A three-dimensional Cartesian coordinate system indicates the power receiver and power transmitter's positions, while $x, y$, and $z$ represent the horizontal, vertical, and height axis, respectively, with the bottom left as the origin.

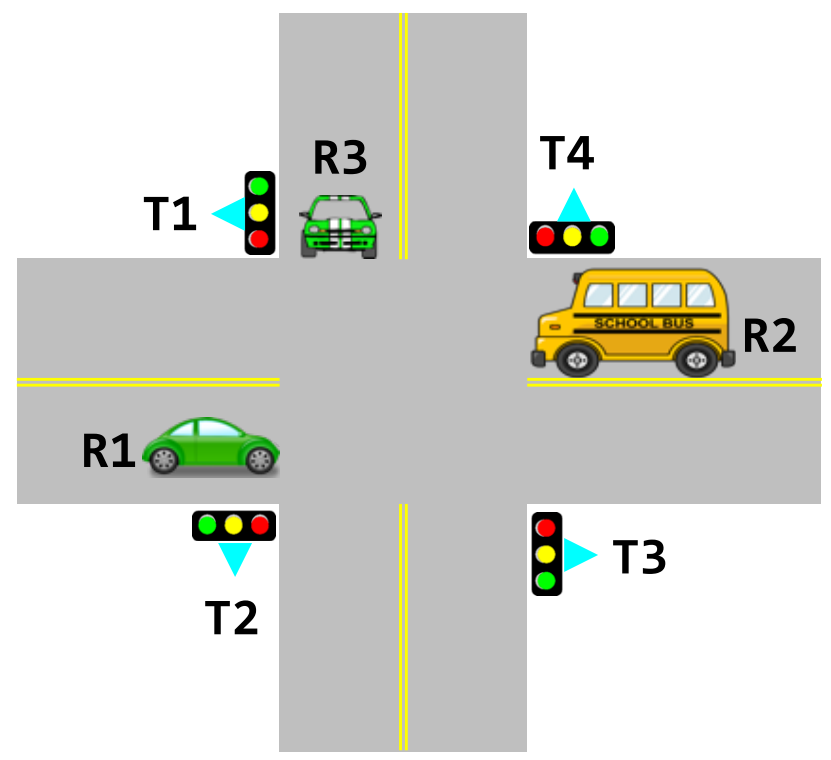

Figure 13. Power transmission simulation environment.

The PTX device is mounted on a traffic light and communicates with an EV via V2I. It transmits pilots and power to a desired WPC using a laser beam capable of controlling the power. The PTX transmits the DS-OCDMA-encoded pilots as a laser beam and transmits the HILPB to the selected WPC. It receives a message to power transmission through V2I and operates accordingly. The four PTXs used in the simulation can transmit different MPT, and their characteristics are shown in Table 4. 
Table 4. Characteristics of the PTXs used in the simulation.

\begin{tabular}{|c|c|c|c|c|c|}
\hline \multicolumn{2}{|c|}{ PTX } & T1 & T2 & T3 & T4 \\
\hline \multicolumn{2}{|c|}{ MTP $(k W)$} & 300 & 250 & 200 & 150 \\
\hline \multicolumn{2}{|c|}{ Location of the PTX $(x, y, z)$} & $(10,18,20)$ & $(10,10,20)$ & $(18,10,20)$ & $(18,18,20)$ \\
\hline \multirow{2}{*}{ WPC } & $\begin{array}{c}\text { Range } \\
(\theta, \phi),\left(^{\circ}\right)\end{array}$ & $\begin{array}{c}(90-180 \\
0-359)\end{array}$ & $\begin{array}{c}(90-180 \\
0-359)\end{array}$ & $\begin{array}{c}(90-180 \\
0-359)\end{array}$ & $\begin{array}{c}(90-180 \\
0-359)\end{array}$ \\
\hline & $\begin{array}{l}\text { Spacing } \\
(\theta, \phi),\left(^{\circ}\right)\end{array}$ & $(1,1)$ & $(1,1)$ & $(1,1)$ & $(1,1)$ \\
\hline \multirow{2}{*}{$\begin{array}{c}\text { HILPB } \\
\text { characteristics }\end{array}$} & Diameter (m) & 0.01 & 0.01 & 0.01 & 0.01 \\
\hline & divergence (rad) & 0.01 & 0.01 & 0.01 & 0.01 \\
\hline
\end{tabular}

In the simulation, V2I-enabled EVs are stopped at intersections, waiting for the light to turn green. EVs that continuously measure the RCPI, convert the HILPB received via the PV array into electricity, and communicate via V2I is used as the PRX. The PRX can broadcast power transmission-request messages to PTXs via V2I and decode and process the laser pilots encoded with DS-OCDMA from PTXs received through the PV array. The three PRXs used in the simulation have different MPQ but are equipped with a PV array with the same surface area and characteristics, as outlined in Table 5.

Table 5. Characteristics of the PRXs used in the simulation.

\begin{tabular}{cccc}
\hline PRX & R1 & R2 & R3 \\
\hline MPQ $(\mathrm{W})$ & 200 & 300 & 150 \\
Location of the PRX $(\mathrm{x}, \mathrm{y}, \mathrm{z})(\mathrm{m})$ & $(7,12,1.5)$ & $(20,16,2)$ & $(12,20,1.5)$ \\
PV array architecture & $5 \times 5$ & $5 \times 5$ & $5 \times 5$ \\
PV array surface area $\left(\mathrm{m}^{2}\right)$ & 1 & 1 & 1 \\
Power conversion efficiency & $30 \%$ & $30 \%$ & $30 \%$ \\
Size of PV array & $1 \mathrm{~m}$ & $1 \mathrm{~m}$ & $1 \mathrm{~m}$ \\
\hline
\end{tabular}

\subsection{Simulation Results}

We used Equations (1)-(7) to calculate the RCPI and the MDP of each WPC. When a PTX receives a PCI request command, it sends its unique ID code at a pulse power of $46 \mu \mathrm{J}$ through all WPCs available for transmission. Table 6 lists the WPCs of the PTXs available for each PRX to receive the largest amount of power. Each cell displays the PCI of the WPC $(\theta, \phi)$ of the given PTX and the RCPI. As defined in Equation (6), the RCPI and MDP vary from a WPC of a PTX to another depending on the strength of the laser beam incident on the PRX.

Tables 7-9 are simulation results of different algorithms for selecting a PTX when PRXs R1 to R3 sequentially request power. Each of the table cells represents the MDP and MPQ of the PRX and the MTP and WPC of the PTX. Completion of PTX-PRX pair has the white color in the corresponding order and then turns to the gray color in the following order. The cells' contents containing '-' indicates that the PTX and PRX have not been paired yet. According to the algorithm, different results could be obtained when the PRX selects an appropriate PTX and generates an optimal WPC. 
Table 6. Possible PTX-PRX combinations according to the maximum receivable power.

\begin{tabular}{ccccc}
\hline \multicolumn{1}{c}{ Parameter } & T1 & T2 & T3 & T4 \\
\hline WPC & $(162,189)$ & $(173,333)$ & $(154,283)$ & $(150,236)$ \\
R1 & PV $(0,-1)$ & PV $(0,-1)$ & PV $(-1,-1)$ & PV $(-1,0)$ \\
Highest irradiance cell location & $44.426 \mu \mathrm{J}$ & $46.678 \mu \mathrm{J}$ & $42.642 \mu \mathrm{J}$ & $39.836 \mu \mathrm{J}$ \\
RCPI of the pilot signal & $289.8 \mathrm{~kW}$ & $248.25 \mathrm{~kW}$ & $185.4 \mathrm{~kW}$ & $129.9 \mathrm{~kW}$ \\
MDP & $96.6 \%$ & $99.3 \%$ & $92.7 \%$ & $86.6 \%$ \\
MTE & $(153,103)$ & $(149,56)$ & $(161,283)$ & $(173,153)$ \\
R2 & PV $(-1,-1)$ & PV $(-1,-1)$ & PV $(-1,-1)$ & PV $(0,-1)$ \\
& $42.366 \mu \mathrm{J}$ & $39.836 \mu \mathrm{J}$ & $44.436 \mu \mathrm{J}$ & $45.678 \mu \mathrm{J}$ \\
Highest irradiance cell location & $276.3 \mathrm{~kW}$ & $216.5 \mathrm{~kW}$ & $193.2 \mathrm{~kW}$ & $148.95 \mathrm{~kW}$ \\
RCPI of the pilot signal & $92.1 \%$ & $86.6 \%$ & $96.6 \%$ & $99.3 \%$ \\
MDP & $(173,63)$ & $(154,13)$ & $(150,326)$ & $(162,279)$ \\
MTE & PV $(0,0)$ & PV $(0,0)$ & PV $(-1,0)$ & PV $(0,0)$ \\
R3 & $45.678 \mu \mathrm{J}$ & $42.642 \mu \mathrm{J}$ & $39.836 \mu \mathrm{J}$ & $44.436 \mu \mathrm{J}$ \\
Highest irradiance cell location & $297.9 \mathrm{~kW}$ & $231.75 \mathrm{~kW}$ & $173.2 \mathrm{~kW}$ & $144.9 \mathrm{~kW}$ \\
RCPI of the pilot signal & $99.3 \%$ & $92.7 \%$ & $86.6 \%$ & $96.6 \%$ \\
\hline MDP & & &
\end{tabular}

\subsubsection{Pairing Algorithm Based on Maximum Receivable Power}

Table 7 and Figure 14 are simulation results of the first pairing algorithm in which the PTX that can provide the most significant power is selected by calculating the product of MTP and PTE of PTX. When the power provided by the first selected PTX is insufficient, PTXs that provide the most significant power to compensate for the insufficient amount of power are sequentially selected. In the first round, the PRX R1 selected PTX T1, transmitting the most significant power among all the PTXs. The PRX R1 received $289.8 \mathrm{~kW}$ power through the WPC $(162,189)$ of PTX T1, which is greater than the MDP $200 \mathrm{~kW}$. The pair between PRX R1 and PTX T1 is established, and then desired power is supplied. In the second round, the PRX R2 selects PTX T2 and T3, transmitting the highest power among the remaining PTXs. PRX R2 received power from PTX T2 and T3 together, so it received $409.7 \mathrm{~kW}$ of power then the MDP $300 \mathrm{~kW}$. The PTX T2 used a WPC $(173,333)$, and the PTX T3 used a WPC $(154,283)$. In the third round, the PRX R3 received power from the unallocated PTX T4 and provides $144.9 \mathrm{~kW}$, which is lower than the required power of $150 \mathrm{~kW}$. When the algorithm for selecting the PTX with the most significant MTP is used, the PTX with the most significant maximum transmission power is paired in turn, regardless of the MDP of the PRX. Finally, the PRX R1 provided $145 \%$ of the MDP, the PRX $\mathrm{R} 2$ received $145 \%$, but the PRX R3 received $87 \%$ less power. 
Table 7. Results of WPC using the highest power-based PTX selection algorithm.

\begin{tabular}{|c|c|c|c|c|}
\hline & & \multicolumn{3}{|c|}{ PRX-PTX Pairing Sequences } \\
\hline & & First Round & Second Round & Third Round \\
\hline \multirow{3}{*}{ PRX } & $\mathrm{R} 1$ & $289.8 \mathrm{~kW}, 200 \mathrm{~kW}$ & $289.8 \mathrm{~kW}, 200 \mathrm{~kW}$ & $289.8 \mathrm{~kW}, 200 \mathrm{~kW}$ \\
\hline & R2 & - & $433.65 \mathrm{~kW}, 300 \mathrm{~kW}$ & $433.65 \mathrm{~kW}, 300 \mathrm{~kW}$ \\
\hline & R3 & - & - & $129.9 \mathrm{~kW}, 150 \mathrm{~kW}$ \\
\hline \multirow{4}{*}{ PTX } & $\mathrm{T} 1$ & $(162,189), 300 \mathrm{~kW}$ & $(162,189), 300 \mathrm{~kW}$ & $(162,189), 300 \mathrm{~kW}$ \\
\hline & $\mathrm{T} 2$ & - & $(173,333), 250 \mathrm{~kW}$ & $(173,333), 250 \mathrm{~kW}$ \\
\hline & $\mathrm{T} 3$ & - & $(154,283), 200 \mathrm{~kW}$ & $(154,283), 200 \mathrm{~kW}$ \\
\hline & $\mathrm{T} 4$ & - & - & $(150,236), 150 \mathrm{~kW}$ \\
\hline
\end{tabular}

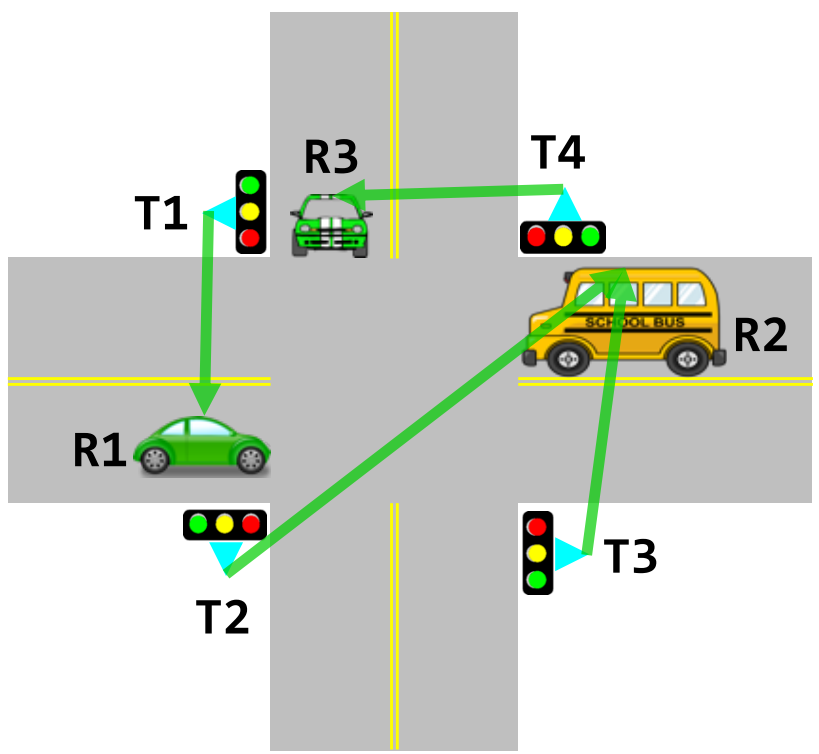

Figure 14. Results of power transmission path establishment.

\subsubsection{Pairing Algorithm Based on Least Receivable Power}

In the second pairing algorithm, the PRX chooses the PTX with the least power first, as illustrated in Table 8 and Figure 15. If the first chosen PTX did not have a sufficient power supply due to lacking MTP, the PRX picks additional PTX with the smallest MPT among the remainings. In the first round, the PRX R1 chose PTX T3 and T4, transmitting the smallest power among PTXs. PRX R1 received $315.3 \mathrm{~kW}$ power, which is greater than the required power of $200 \mathrm{~kW}$. The PTX T3 used WPC $(161,283)$, and T4 used WPC $(173,153)$. In the second round, the PRX R2 chose PTX T1 and T2, transmitting the smallest power among the remaining PTXs. PRX R2 received power $492.8 \mathrm{~kW}$ from PTX T1 and T2 together, greater than the MPQ of $300 \mathrm{~kW}$. The PTX T1 used a WPC $(153,103)$, and the PTX T2 used a WPC $(149,56)$. In the third round, PRX R3 could not receive any power because there was no unassigned PTX. Using this algorithm, the PRX selects the PTX that can provide the smallest power first, regardless of the amount of power required by the PRX, and then select an additional PTX that can provide the second smallest power. So, the PRX received power from two PTXs at the same time, not from one PTX. As a result, PRX R1 received $158 \%$ of the MPQ from the two PTXs, PRX R2 provided $164 \%$ of the MPQ from both places, and PRX R3 has no provider. 
Table 8. Results of WPC using the least power-based PTX selection algorithm.

\begin{tabular}{|c|c|c|c|c|}
\hline & & \multicolumn{3}{|c|}{ PRX-PTX Pairing Sequences } \\
\hline & & First Round & Second Round & Third Round \\
\hline \multirow{3}{*}{ PRX } & R1 & $315.3 \mathrm{~kW}, 200 \mathrm{~kW}$ & $315.3 \mathrm{~kW}, 200 \mathrm{~kW}$ & $315.3 \mathrm{~kW}, 200 \mathrm{~kW}$ \\
\hline & $\mathrm{R} 2$ & - & $492.8 \mathrm{~kW}, 300 \mathrm{~kW}$ & $492.8 \mathrm{~kW}, 300 \mathrm{~kW}$ \\
\hline & R3 & - & - & $0 \mathrm{~kW}, 150 \mathrm{~kW}$ \\
\hline \multirow{4}{*}{ PTX } & $\mathrm{T} 1$ & - & $(153,103), 300 \mathrm{~kW}$ & $(153,103), 300 \mathrm{~kW}$ \\
\hline & $\mathrm{T} 2$ & - & $(149,56), 250 \mathrm{~kW}$ & $(149,56), 250 \mathrm{~kW}$ \\
\hline & $\mathrm{T} 3$ & $(161,283), 200 \mathrm{~kW}$ & $(161,283), 200 \mathrm{~kW}$ & $(161,283), 200 \mathrm{~kW}$ \\
\hline & $\mathrm{T} 4$ & $(173,153), 150 \mathrm{~kW}$ & $(173,153), 150 \mathrm{~kW}$ & $(173,153), 150 \mathrm{~kW}$ \\
\hline
\end{tabular}

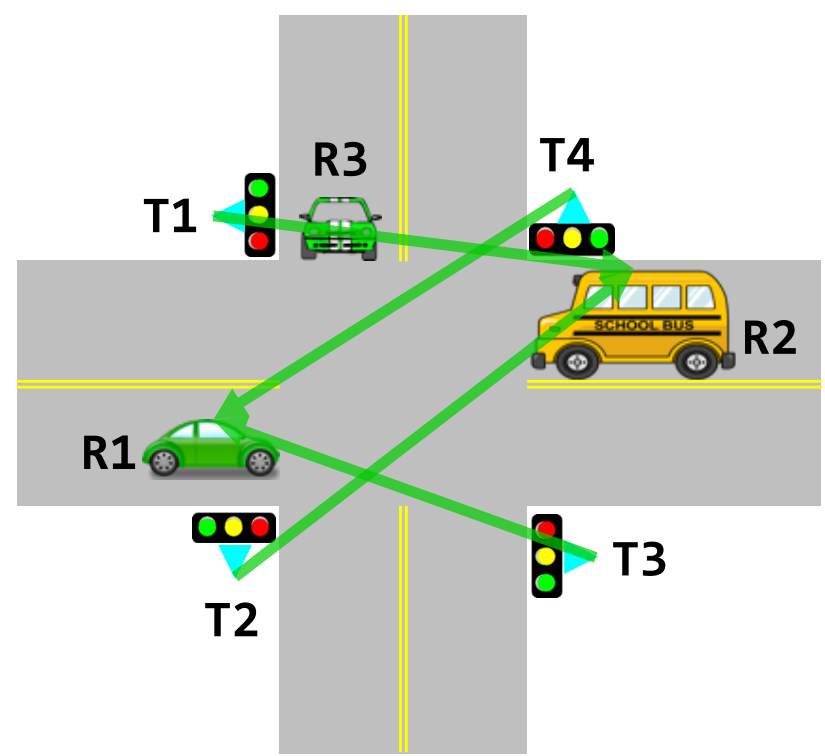

Figure 15. Results of power transmission path establishment.

\subsubsection{Pairing Algorithm Based on the Best PTE Power}

Table 9 and Figure 16 are simulation results of the third pairing algorithm in which the PRX chose the PTX with the best PTE first. When the power provided by the first chosen PTX is insufficient, the PTX having the next best PTE is sequentially selected. The PTX selection process continues until all the necessary power is provided. In the first round, the PRX R1 selects PTX T2 as the transmitter, which has the best transmission rate among the PTXs. It then receives the power of $231.75 \mathrm{~kW}$ through the WPC $(154,13)$ that is more than the required power of $200 \mathrm{~kW}$. In the second round, the PRX R2 selected PTX T3 and T4, which have the subsequent best transmission rates, among the remaining PTXs. PRX R2 received $318.1 \mathrm{~kW}$ power from PTX T3 and T4 simultaneously, which is greater than the required power of $300 \mathrm{~kW}$. The PTX T3 used WPC $(150,326)$, and the PTX T4 used WPC $(162,279)$. In the third round, the PRX R3 received power from the unallocated PTX T1. It was able to receive $297.9 \mathrm{~kW}$ power, which is higher than the required power of $150 \mathrm{~kW}$. With the algorithm that selects the PTX with the best PTE, the PTXs with the highest PTE are allocated first regardless of the power receiver's power requirement. As a result, the PRX R1 received $116 \%$ of the required power, the PRX R2 received $106 \%$, and the PRX R3 received $197 \%$ of the required power. 
Table 9. Results of WPC using the best PTE-based PTX selection algorithm.

\begin{tabular}{|c|c|c|c|c|}
\hline & & \multicolumn{3}{|c|}{ PRX-PTX Pairing Sequences } \\
\hline & & First Round & Second Round & Third Round \\
\hline \multirow{3}{*}{ PRX } & R1 & $231.75 \mathrm{~kW}, 200 \mathrm{~kW}$ & $231.75 \mathrm{~kW}, 200 \mathrm{~kW}$ & $231.75 \mathrm{~kW}, 200 \mathrm{~kW}$ \\
\hline & R2 & - & $318.1 \mathrm{~kW}, 300 \mathrm{~kW}$ & $318.1 \mathrm{~kW}, 300 \mathrm{~kW}$ \\
\hline & R3 & - & - & $297.9 \mathrm{~kW}, 150 \mathrm{~kW}$ \\
\hline \multirow{4}{*}{ PTX } & $\mathrm{T} 1$ & - & - & $(173,63), 300 \mathrm{~kW}$ \\
\hline & $\mathrm{T} 2$ & $(154,13), 250 \mathrm{~kW}$ & $(154,13), 250 \mathrm{~kW}$ & $(154,13), 250 \mathrm{~kW}$ \\
\hline & $\mathrm{T} 3$ & - & $(150,326), 200 \mathrm{~kW}$ & $(150,326), 200 \mathrm{~kW}$ \\
\hline & $\mathrm{T} 4$ & - & $(162,279), 150 \mathrm{~kW}$ & $(162,279), 150 \mathrm{~kW}$ \\
\hline
\end{tabular}

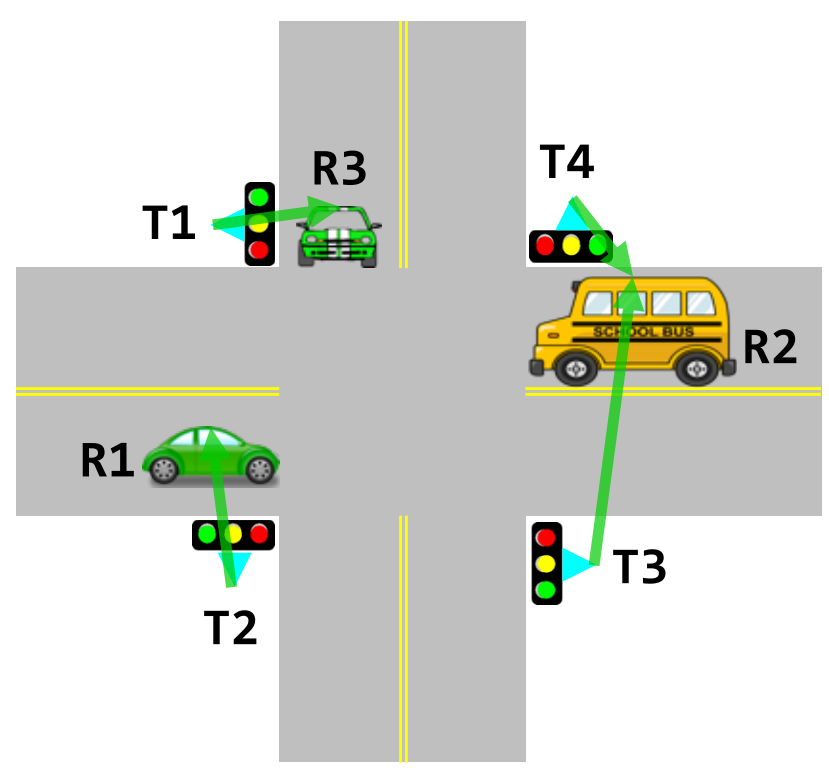

Figure 16. Results of power transmission path establishment.

The PTE varies according to the distance and geometric position between the PTX and the PRX. According to their characteristics and arrangement, the pairing between the PTX and the PRX is different in the three algorithms. Among the three algorithms, only the third algorithm that selects the PTX with the best PTE first successfully provides the power required by all PRX. Since HILPB is heavily influenced by PTX characteristics (MTP, MTE), PRX characteristics (MPQ), and the geometric placement relationship between PTX and PRX, it is possible to use various allocation algorithms to create the PRX-PTX pairs appropriately. Besides, the battery's priority and charging time in the EV vary depending on the amount of remaining power, so it is more effective to allocate all the power needed to the priority battery by stopping all other receivers.

\section{Conclusions}

Research on WPT is attracting attention to miniaturizing EVs' batteries and increasing the charging range. Despite the most studied methods, magnetic induction and magnetic resonance using coils can transmit power only up to several meters; thus, the existing road infrastructure needs to be changed to use these methods for charging EVs. On the other hand, using microwaves and lasers, which have been used to charge unmanned aerial vehicles and satellites at a distance of several kilometers or more, is relatively easy desiring no change in road infrastructure. Using microwaves for charging is restricted by many 
limitations, such as radiation, low rate of charging, radio wave interference, etc. But using a laser beam involves no interference phenomenon and power can be received from several charging units simultaneously.

This paper discussed a method for selecting the optimal PTX for a PRX to fulfill its MPQ in an environment with multiple PTXs and PRXs, such as an EV. We modeled the MDP by a PRX with a PV array depending on the geometric relationship between the PTX and PRX. The simulation environment contains three PRX and four PTX where the communication occurs using a DS-OCDMA system. Three different schemes are tested wherein the PTX is selected based on the highest PTE power, least PTE power, and the best PTE power to meet the energy requirement of a PRX. It was verified that optimal PTXs are allocated for power transmission to PRXs in which three PRXs with different MPQs sequentially send power transmission requests to four PTXs with different MTPs. The MPQ of each PRX is satisfied by applying the algorithm to select the PTX according to the alignment and characteristics of the PTXs and PRXs. Results indicate that the third scheme where the selection of the PTX is based on the best PTE fulfills the PTE requirements of all the PTXs.

This study can be extended to rearrange the PV arrays mounted on the PRX to enhance the MDP and the PTE by optimizing the power distribution of the PV array. Furthermore, considering that the charging time differs depending on the residual power of the battery embedded in an EV, a PTX can continue to transmit power to another PRX after completing the transmission of power to the first PRX, depending on the waiting time at a red traffic light. Given the importance of an algorithm for selecting the optimal PTX in an environment where multiple PTXs can transmit power to a PRX in need of power supply or several PTXs can transmit the required power simultaneously, additional research is required to develop algorithms for selecting PTXs in different circumstances. For applications in the real world, the method must be further enhanced to ensure safety for moving EVs.

Author Contributions: Conceptualization, G.K. and J.E.; Data curation, G.K.; Formal analysis, I.A.; Funding acquisition, Y.P.; Investigation, J.E.; Methodology, G.K.; Project administration, Y.P.; Resources, G.K.; Software, I.A.; Supervision, Y.P.; Validation, G.K., I.A., and J.E.; Visualization, I.A.; Writing—original draft, G.K.; Writing—review \& editing, I.A. All authors have read and agreed to the published version of the manuscript.

Funding: This research was supported by Basic Science Research Program through the National Research Foundation of Korea (NRF) funded by the Ministry of Science, ICT and Future Planning (2017R1E1A1A01074345). This research was also supported by the MSIT (Ministry of Science and ICT), Korea, under the ITRC (Information Technology Research Center) support program (IITP-2020-2016-000313) supervised by the IITP (Institute for Information \& communication Technology Promotion).

Institutional Review Board Statement: Not applicable.

Informed Consent Statement: Not applicable.

Data Availability Statement: Not applicable.

Conflicts of Interest: The authors declare no conflict of interest. The funders had no role in the design of the study; in the collection, analyses, or interpretation of data; in the writing of the manuscript, or in the decision to publish the results. 


\begin{tabular}{|c|c|}
\hline \multicolumn{2}{|c|}{ Abbreviations } \\
\hline \multicolumn{2}{|c|}{ The following abbreviations are used in this manuscript: } \\
\hline AlN & Aluminum nitride \\
\hline ANSI & American National Standard Institute \\
\hline COTS & Commercial off the shelf \\
\hline DS-OCDMA & Direct-sequence optical code division multiple access \\
\hline EV & Electric vehicle \\
\hline HILPB & High-intensity laser power beaming \\
\hline MPQ & Maximum power requirement \\
\hline MTP & Maximum transmission power \\
\hline PCI & Power channel information \\
\hline PPC & Photovoltaic power conversion \\
\hline PRXs & Power receivers \\
\hline PTE & Power transfer efficiency \\
\hline PTXs & Power transmitters \\
\hline PV & Photovoltaic \\
\hline RCPI & Received channel power indicator \\
\hline $\mathrm{TCO}$ & Total cost of ownership \\
\hline TEC & Thermoelectric cooler \\
\hline V2I & Vehicle-to-infrastructure \\
\hline VMJ & Vertical multi-junction \\
\hline WPC & Wireless power channel \\
\hline WPT & Wireless power transmission \\
\hline
\end{tabular}

\section{References}

1. China, M. China Vehicle Environmental Management Annual Report 2016; Ministry of Ecology and Environment of the People's Republic of China: Beijing, China, 2016.

2. Ashfaq, M.; Butt, O.; Selvaraj, J.; Rahim, N. Assessment of electric vehicle charging infrastructure and its impact on the electric grid: A review. Int. J. Green Energy 2021, 18, 1-30. [CrossRef]

3. El-Bayeh, C.Z.; Alzaareer, K.; Aldaoudeyeh, A.M.I.; Brahmi, B.; Zellagui, M. Charging and Discharging Strategies of Electric Vehicles: A Survey. World Electr. Veh. J. 2021, 12, 11. [CrossRef]

4. Li, S.; Mi, C.C. Wireless Power Transfer for Electric Vehicle Applications. IEEE J. Emerg. Sel. Top. Proc. 2015, 3, 4-17. [CrossRef]

5. Baronti, F.; Chow, M.Y.; Ma, C.; Rahimi-Eichi, H.; Saletti, R. E-transportation: The Role of Embedded Systems in Electric Energy Transfer from Grid to Vehicle. EURASIP J. Embed. Syst. 2016, 2016, 11. [CrossRef]

6. $\quad$ Bi, Z.; Kan, T.; Mi, C.C.; Zhang, Y.; Zhao, Z.; Keoleian, G.A. A Review of Wireless Power Transfer for Electric Vehicles: Prospects to Enhance Sustainable Mobility. Appl. Energy 2016, 179, 413-425. [CrossRef]

7. Shadid, R.; Noghanian, S.; Nejadpak, A. A literature survey of wireless power transfer. In Proceedings of the 2016 IEEE International Conference on Electro Information Technology (EIT), Grand Forks, ND, USA, 19-21 May 2016; pp. 0782-0787.

8. Di Capua, G.; Sánchez, J.A.; Cabrera, A.T.; Cabrera, D.F.; Femia, N.; Petrone, G.; Spagnuolo, G. A losses-based analysis for electric vehicle wireless chargers. In Proceedings of the 2015 International Conference on Synthesis, Modeling, Analysis and Simulation Methods and Applications to Circuit Design (SMACD), Istanbul, Turkey, 7-9 September 2015; pp. 1-4.

9. Summerer, L.; Purcell, O. Concepts for Wireless Energy Transmission via Laser; Report; Europeans Space Agency (ESA)-Advanced Concepts Team: Noordwijk, The Netherlands, 2009.

10. Nugent, T.J., Jr.; Kare, J.T. Laser Power Beaming for Defense and Security Applications. Int. Soc. Opt. Photonics 2011, 8045, 804514. [CrossRef]

11. Bhatti, A.R.; Salam, Z.; Aziz, M.J.B.A.; Yee, K.P. A Critical Review of Electric Vehicle Charging using Solar Photovoltaic. Int. J. Energy Res. 2016, 40, 439-461. [CrossRef]

12. Sprangle, P.; Hafizi, B.; Ting, A.; Fischer, R. High-Power Lasers for Directed-Energy Applications. Appl. Opt. 2015, 54, F201-F209. [CrossRef] [PubMed]

13. Trivi no-Cabrera, A.; González-González, J.M.; Aguado, J.A. Compensation Networks. In Wireless Power Transfer for Electric Vehicles: Foundations and Design Approach; Springer: Berlin/Heidelberg, Germany, 2020; pp. 69-100.

14. Hutchinson, L.; Waterson, B.; Anvari, B.; Naberezhnykh, D. Potential of wireless power transfer for dynamic charging of electric vehicles. IET Intell. Transp. Syst. 2018, 13, 3-12. [CrossRef]

15. Tran, D.H.; Choi, W. Design of a high-efficiency wireless power transfer system with intermediate coils for the on-board chargers of electric vehicles. IEEE Trans. Power Electron. 2017, 33, 175-187. [CrossRef]

16. O'Neill, M.J.; Piszczor, M.F.; Eskenazi, M.I.; McDanal, A.J.; George, P.J.; Botke, M.M.; Brandhorst, H.W.; Edwards, D.L.; Hoppe, D.T. Ultralight Stretched Fresnel Lens Solar Concentrator for Space Power Applications. Int. Soc. Opt. Photonics 2003, 5179, 116-126. [CrossRef] 
17. Osepchuk, J.M. Microwave Policy Issues for Solar Space Power. Space Policy 2000, 16, 111-115. [CrossRef]

18. Christ, A.; Douglas, M.; Nadakuduti, J.; Kuster, N. Assessing Human Exposure to Electromagnetic Fields from Wireless Power Transmission Systems. Proc. IEEE 2013, 101, 1482-1493. [CrossRef]

19. Jiang, H.; Brazis, P.; Tabaddor, M.; Bablo, J. Safety Considerations of Wireless Charger for Electric Vehicles-A review paper. In Proceedings of the 2012 IEEE Symposium on Product Compliance Engineering (ISPCE), Portland, OR, USA, 5-7 November 2012; pp. 1-6. [CrossRef]

20. Dickinson, R.M. Safety issues in SPS wireless power transmission. Space Policy 2000, 16, 117-122. [CrossRef]

21. Duncan, K.J. Laser Based Power Transmission: Component Selection and Laser Hazard Analysis. In Proceedings of the 2016 IEEE PELS Workshop on Emerging Technologies: Wireless Power Transfer (WoW), Knoxville, TN, USA, 4-6 October 2016; pp. 100-103. [CrossRef]

22. Laser Institute of America. ANSI Z136.1-2014: American National Standard for Safe Use of Lasers; Laser Institute of America: Orlando, FL, USA, 2014.

23. Massa, A.; Oliveri, G.; Viani, F.; Rocca, P. Array Designs for Long-Distance Wireless Power Transmission: State-of-the-Art and Innovative Solutions. Proc. IEEE 2013, 101, 1464-1481. [CrossRef]

24. Ahn, D.; Hong, S. Effect of Coupling between Multiple Transmitters or Multiple Receivers on Wireless Power Transfer. IEEE Trans. Ind. Electron. 2013, 60, 2602-2613. [CrossRef]

25. Lee, K.; Cho, D.H. Diversity Analysis of Multiple Transmitters in Wireless Power Transfer System. IEEE Trans. Magn. 2013, 49, 2946-2952. [CrossRef]

26. Johari, R.; Krogmeier, J.V.; Love, D.J. Analysis and Practical Considerations in Implementing Multiple Transmitters for Wireless Power Transfer via Coupled Magnetic Resonance. IEEE Trans. Ind. Electron. 2014, 61, 1774-1783. [CrossRef]

27. Mou, X.; Sun, H. Wireless Power Transfer: Survey and Roadmap. In Proceedings of the 2015 IEEE 81st Vehicular Technology Conference (VTC Spring), Glasgow, UK, 11-14 May 2015; pp. 1-5. [CrossRef]

28. Jin, K.; Zhoum, W. Wireless laser power transmission: A review of recent progress. IEEE Trans. Power Electron. 2019, 34, 3842-3859. [CrossRef]

29. Ortabasi, U.; Friedman, H.W. PowerSphere: A Novel Photovoltaic Cavity Converter Using Low Bandgap TPV Cells for Efficient Conversion of High Power Laser Beams to Electricity. AIP Conf. Proc. 2004, 738, 142-152. [CrossRef]

30. Ortabasi, U.; Friedman, H. Powersphere: A Photovoltaic Cavity Converter for Wireless Power Transmission using High Power Lasers. In Proceedings of the 2006 IEEE 4th World Conference on Photovoltaic Energy Conference, Waikoloa, HI, USA, 7-12 May 2006; Volume 1, pp. 126-129. [CrossRef]

31. Zhou, W.; Jin, K. Optimal Photovoltaic Array Configuration under Gaussian Laser Beam Condition for Wireless Power Transmission. IEEE Trans. Power Electr. 2016. [CrossRef]

32. MH GoPower Company. MH VMJ PV Cell-Array Datasheet; MH GoPower Company: Kaohsiung City, Taiwan, 2016.

33. Driggers, R.G.; Hoffman, C.; Driggers, R., Eds. Encyclopedia of Optical Engineering; CRC Press: Boca Raton, FL, USA, 2003.

34. Sabatini, R.; Richardson, M.A. Airborne Laser Systems Testing and Analysis; Report; NATO Science and Technology Organization: Brussels, Belgium, 2010.

35. Haydaroglu, I.; Mutlu, S. Optical Power Delivery and Data Transmission in a Wireless and Batteryless Microsystem Using a Single Light Emitting Diode. J. Microelectromech. Syst. 2015, 24, 155-165. [CrossRef]

36. Wu, C.W.; Wang, J.; Huang, C.G. A coupled model on energy conversion in laser power beaming. J. Power Sour. 2018, 393, 211-216. [CrossRef]

37. Goursaud-Brugeaud, C.; Julien-Vergonjanne, A.; Cances, J.P. Prime Code Efficiency in DS-OCDMA Systems using Parallel Interference Cancellation. J. Commun. 2007, 2, 51-57. [CrossRef]

38. Yang, G.C.; Kwong, W.C. Prime Codes with Applications to CDMA Optical and Wireless Networks; Artech House: Norwoord, MA, USA, 2002.

39. Kwong, W.C.; Yang, G.C. Optical Coding Theory with Prime; CRC Press: Boca Raton, FL, USA, 2013.

40. Ghafouri-Shiraz, H.; Karbassian, M.M. Optical CDMA Networks: Principles, Analysis and Applications; John Wiley \& Sons: Hoboken, NJ, USA, 2012.

41. Kim, G.; Park, Y. LIDAR Pulse Coding for High Resolution Range Imaging at Improved Refresh Rate. Opt. Express 2016, 24, 23810-23828. [CrossRef] [PubMed]

42. Kim, G.; Park, Y. Independent Biaxial Scanning Light Detection and Ranging System Based on Coded Laser Pulses without Idle Listening Time. Sensors 2018, 18, 2943. [CrossRef] [PubMed]

43. Kim, G.; Park, Y. Suitable combination of direct intensity modulation and spreading sequence for LIDAR with pulse coding. Sensors 2018, 18, 4201. [CrossRef] [PubMed] 